\title{
We Expect Stocks to Rise, but We Do Not Know When and Which Ones: Excessive Optimism in Predicting Future Stock Indices Returns
}

\author{
Matúš Grežo \\ Institute of Experimental Psychology \\ Center of Social and Psychological Sciences, Slovak Academy of Sciences
}

\begin{abstract}
In this study, we analyze whether: 1) financial professionals manifest lower excessive optimism in predicting future stock indices returns; 2) excessive optimism occurs more when predicting future returns of indices reporting profits than indices reporting losses 3) more long-term predictions are more optimistic than short-term predictions. Three groups of participants $(\mathrm{n}=$ 251 ) - investment managers, financial advisors, and lay men predicted future returns of six stock indices in three forecasting horizons by estimating the $95 \%$ confidence intervals. The results showed a high inaccuracy in all three groups. The most accurate group was a group of investment managers, followed by lay men and advisors. We also found that $93 \%$ of all incorrect predictions were over-optimistic and excessive optimism was much higher when forecasting stock indices that reported profits in the recent past. The results of this research did not confirm previous findings about inverse effect of expertise in predicting future returns of financial assets.
\end{abstract}

Key words: excessive optimism, financial professionals, forecasting

\section{Introduction}

In his book supporting a random walk theory, economist Burton Malkiel (1973/2016, p. 26) says that ,a blindfolded monkey throwing darts at a newspaper's financial pages could select a portfolio that would do just as well as one carefully selected by experts." In 1988, the Wall Street Journal decided to test this theory and created the Dartboard Contest where ev-

\footnotetext{
This work was supported by the Slovak Research and Development Agency under the contract No. APVV-0361-12.

Correspondence concerning this article should be addressed to Matúš Grežo, Institute of Experimental Psychology, Center of Social and Psychological Sciences, Slovak Academy of Sciences, Dúbravská cesta 9, 84104 Bratislava, Slovak Republic. E-mail: matus.grezo@savba.sk
}

Received November 15, 2016 ery month four financial experts chose four stocks and competed with a ,blindfolded mon$k e y^{\text {" }}$ which was represented by the Wall Street Journal staff members throwing darts at a newspaper's stock list. Every month these two portfolios competed in profitability. After 100 contests, it was shown that experts won 61 times and the dart throwers won 39. Some authors further examined these results. Baer and Gensler (2002) calculated profits in longer time horizons of 12 and 24 months and found that after 12 months the portfolio profitability of dart throwers and experts was equal and after 24 months dart throwers beat experts in $55 \%$ to $45 \%$ of the time. Liang, Ramchander and Sharma (1995) also analyzed results of the Dartboard Contest and found that portfolios of experts beat darts only in the very short time period of one week after publishing their picks in the Wall Street Journal. When analyzing more long-term horizons of one and two months, the difference was not significant and after four and six 
months portfolios of darts were more profitable.

Despite a lot of deficiencies in this content (e.g., ignoring risk or dividends), the results clearly showed that professional investor using a variety of sophisticated methods of analyzing information cannot systematically provide accurate predictions and beat the market or even lay uninformed investor. In this paper, the observation and comparison of forecasting ability of lay people and financial professionals is the main object. More specifically, the main goal is to observe the excessive optimism in predicting future stock indices returns. We want to know whether: a) financial professionals manifest lower excessive optimism in predicting future returns; $b$ ) excessive optimism occurs more when predicting future returns of indices reporting profits than indices reporting losses; c) more long-term predictions are more optimistic than short-term predictions.

\section{Defining Excessive Optimism and Distin- guishing it from other Related Constructs}

Although there is some inconsistency in terminology among authors when defining optimism (excessive optimism, managerial optimism, optimism bias), this construct is defined as expectations that are excessively positive and biased compared to the objective reality (Shefrin, 2007; Heaton, 2002). In investment and finance works (e.g., Wang, Sheng, \& Yang, 2013; Heaton, 2002; Kafayat, 2014), excessive optimism is mostly associated with Weinstein's concept of unrealistic optimism (Weinstein, 1980). These authors often use its main postulate that people systematically overestimate the probability of experiencing positive events and underestimate chances of experiencing negative events. However, what is different here is the absence of comparison of one's probabilities with the probabilities of other people. Instead of this, excessive optimism is based on comparing one's expectations about the event with the real objective data of how the event ended up. Another similar psychological concept that is widely associated with excessive optimism, mostly by authors from behavioral finance field, is overconfidence (e.g., Hilary, Hsu, \& Segal, 2013; Hilton, Régner, Cabantous, Charalambides, \& Vautier, 2011). More specifically, excessive optimism is mostly associated with one particular overconfidence construct the miscalibration of probabilities. Here, the subject is asked to indicate how precise his knowledge is by specifying, for example, a $90 \%$ confidence interval around estimates of some quantities. Provided confidence interval is subsequently compared with the real actual quantity. To be more specific, in the overconfidence research on estimating future returns of investments, participant is asked to provide confidence intervals in which $\mathrm{s} / \mathrm{he}$ is $90 \%$ sure that the actual future return will fall in. After a predicted time period, the researcher analyzes whether real actual return (e.g., 4\%) fell into the estimated interval (e.g., 2-15\%) and results show whether the prediction was accurate or not. As can be seen, in defining miscalibration one's expectations about the future are compared to the actual real future state, which is of similar characteristic as in the operationalization of excessive optimism. However when observing excessive optimism, we go further in the data analyses and examine not just the accuracy of prediction but also, if the prediction was not accurate, whether the real actual return was above (pessimism) or under (optimism) the estimated interval.

Due to the similarity of constructs, research studies on excessive optimism and miscalibration in the field of investment are very close and complementary. Many authors found that predictions of financial professionals about the future returns of assets are very inaccurate and miscalibrated (Barber \& Odean, 2001; BenDavid, Graham, \& Harvey, 2010; Sonsino $\&$ Regev, 2013). In addition, it was shown that 
predictions of professionals are often more inaccurate than predictions of lay people and this lead to a conception of a hypothesis about an inverse effect of expertise in predicting (Staël von Holstein, 1972; Yates, McDaniel, \& Brown, 1991; Menkhoff, Schmeling, \& Schmidt, 2013; Glaser, Langer, \& Weber, 2005). What is important is that the research on excessive optimism extends these results and shows that these inaccurate predictions are biased mostly positively (see reviews by Brown, 1993; and Kothari, 2001).

\section{Excessive Optimism of Investment Managers and Financial Analysts}

Shiller (2000) in his work provides many analyses of historical events but also many research studies that indicate the investors and analysts' great tendency to have overly optimistic expectations concerning financial markets and future returns of assets. He reported the data of Zacks Investment Research Company, which investigated 6000 recommendations of financial analysts about companies. It was shown that only $1 \%$ of these recommendations were "sells", while $69.5 \%$ were "buys" and 29.9\% were "holds". Very similar research, conducted in our geographical location, was conducted by Kohout (2013). He analyzed 65291 recommendations of financial analysts and showed that they were correct roughly in $50 \%$ of cases. What is more, financial analysts manifested excessive optimism with most of their recommendations being "buy" and "certainly buy". Another work on excessive optimism of financial professionals was published by Sharpe (2002), who observed analysts' expectations about the growth of the S\&P 500 stock index. The author found that expectations exceeded actual growth of S\&P 500 in sixteen of the eighteen years between 1979 and 1996, the average difference between the projected and real growth being $9 \%$ points.
Some of the research studies on excessive optimism in investment use questionnaires instead of databases of analysts' predictions. One of such studies was conducted by DeBondt (1998). He longitudinally observed predictions of 45 individual investors about the Dow Jones Industrial Average stock index (DJIA) returns and also the returns of the shares they own. The results showed that investors were overoptimistic about the performance of shares they owned but not about the performance of the DJIA. Another research using questionnaire methodology was conducted by Toshino and Suto (2004), who analyzed predictions of 488 investment managers of 48 Japanese institutional investors. Their results also showed that investment managers were excessively optimistic. It was also shown that optimism was higher when predicting returns of domestic Japanese stock index. Another specific finding was that optimism was significantly greater when the forecasting period was longer. Toshino and Suto (2004) lacked the theoretical explanation for the relationship between forecasting period and excessive optimism. Based on our analyses of research studies on this topic to date, it seems that this phenomenon was largely not observed. We found only two other pieces of evidence supporting a positive relation between optimism and forecast horizon in the works of Kang, O'Brien, and Sivaramakrishnan (1994) and Ramnath, Rock, and Shane (2008), although they also lack the theoretical explanation of this phenomenon.

In addition to the above mentioned works, the great tendency of investors and analysts to provide excessively optimistic predictions was reported by several other authors (e.g., Abarbanell \& Lehavy, 1993; Bradshaw, 2011; DeBondt \& Thaler, 1990; Easterwood $\&$ Nutt, 1999). Moreover, it was shown that excessive optimism is manifested mostly when analyzing companies which reported losses in the recent past (Dowen, 1996; Hwang, Jan, \& 
Basu, 1996; Brown, 1998). In the study of Hwang, Jan and Basu (1996), excessive optimism was ten times higher when analyzing non-profitable companies compared to the profitable ones. Brown (1998) also found that predictions of non-profitable companies are more optimistic than those of profitable companies, where sometimes excessive pessimism may occur. Similar results were also provided by Mande, Wohar and Ortman (2003).

Although many research studies confirm the systematic tendency of financial professionals to have optimistic expectations, fewer studies provide explanations about why this tendency occurs and what are the predictors of such biased reasoning. One particular explanation was proposed by DeBondt and Thaler (1990), who suggested that excessive optimism in investment is caused by overreaction to firms' past performance and underestimation of the fact that performance tends to mean-revert. This overreaction causes prices to be driven too high above or too low below their actual fundamental values and causes the so-called winner-loser effect (DeBondt \& Thaler, 1985). Another study, explaining excessive optimism due to overreaction, was published by Easterwood and Nutt (1999). They found that analysts tend to systematically misinterpret new information about the investment; they underreact to negative information, but overreact to positive information. The issue of misinterpreting new information and past historical changes is also one of the main explanations of excessive optimism in works of Fuster, Herbert, and Laibson (2011; 2012) and Fuster, Laibson, and Mendel (2010). In these papers, the authors suggest that in the process of predicting future prices of assets or markets, subjects use both rational analytic strategies and more simplex heuristic models, which fasten the reasoning about the dynamics of fundamental economic factors. These simple models of reasoning are very comprehensible and easy to apply. Fuster, Laibson and Mendel (2010) call it the natural expectations. What is important is that these expectations turn out to be sophisticated and accurate in capturing the short-run momentum, but fail to reflect a longrun mean reversion because the economy has more long-horizon hump-shaped dynamics than the agents expect from their intuitive models. To paraphrase Fuster, Laibson, and Mendel (2010), people with natural expectations tend to overestimate the long-term persistence of good news or bad news, which on a macroeconomic level causes cyclic excessive optimism.

Besides cognitive factors, there are also some pragmatic reasons for excessive optimism that are related to the nature of investment business. Francis and Philbrick (1993) suggest that the nature of work environment of financial analysts strongly encourages them to report optimistic forecasts, because negative reports could negatively influence their relationships with management and investors. Their findings showed that when analysts recommended "sell" or "hold" the stocks, the predicted return of these stocks was significantly more optimistic, compared to the stocks where the given recommendation was "buy". The very similar pragmatic reasons in explaining excessive optimism was described by Lin, Chang, Chen, and Liao (2013). They state that financial analysts often work in banks and investment companies that have positive relationships with the firms that are analyzed. Practically, the employer (indirectly) forces analysts to provide optimistic predictions in order to preserve a good relationship. Michaely and Womack (1999) also describe this issue and they emphasize that it is an evident conflict of interest. On the one hand, analysts are trying to provide a good service for their clients, on the other hand, they also want to help their employer by creating a positive picture about companies and firms in which the employer has invested capital.

When explaining the excessive optimism of financial professionals, it is difficult to deter- 
mine which of the two above-mentioned aspects (biased information processing or the nature of investment business) play a greater role. However, research using questionnaire methodology (DeBondt, 1998; Toshino \& Suto, 2004) has shown excessive optimism in laboratory conditions as well. In these studies participants were not forced to provide excessively positive predictions but contrary, they were motivated to provide accurate estimates.

\section{The Present Study}

The main purpose of this study was to investigate and compare the accuracy of Slovak financial professionals and lay people in predicting future returns of stock indices. Previous research showed that the predictions of financial professionals in the investment field were rather inaccurate and excessively optimistic (Shiller, 2000; Abarbanell \& Lehavy, 1993; Kothari, 2001; Bradshaw, 2011; DeBondt \& Thaler, 1990; Easterwood \& Nutt, 1999). Moreover, it was shown that professionals were sometimes more inaccurate than the lay people (Staël von Holstein, 1972; Yates, McDaniel, \& Brown, 1991; Menkhoff, Schmeling, \& Schmidt, 2013; Glaser, Langer, \& Weber, 2005). According to these findings, we hypothesized that group of financial professionals would be excessively optimistic in predicting future returns of stock indices. In addition to comparing groups in excessive optimism, we also focused on investigating more specific characteristics of this bias, i.e. whether there are conditions under which excessive optimism occurs more/ less. Based on previous findings (Hwang, Jan, \& Basu, 1996; Brown, 1998; Mande, Wohar, \& Ortman, 2003) we hypothesized that excessive optimism occurs more when predicting future returns of indices reporting profits than indices reporting losses. Finally, a few authors (Toshino \& Suto, 2004; Kang, O’Brien, \& Sivaramakrishnan, 1994; Ramnath, Rock, \&
Shane, 2008) suggested that there is a positive relationship between excessive optimism and forecasted horizon. As we stated before, there is a lack of empirical research in this area. According to these findings we hypothesized that long-term predictions are more optimistic than short-term predictions.

\section{Methods}

\section{Research Sample}

Research sample consisted of 251 participants (162 males and 89 females) divided into three groups: 1) financial professionals from the investment field $\left(n=45 ; A M_{\text {age }}=32.80 ; S D_{\text {age }}=\right.$ $4.22)$ - this group consisted of financial analysts and portfolio managers of institutional investors (further - investment managers); 2) financial professionals outside the investment field of $\left(n=95 ; A M_{\text {age }}=29.75 ; S D_{\text {age }}=6.4\right)$ - this group consisted of financial agents, advisors and bank employees (further - advisors); 3) lay people $\left(n=111 ; A M_{\text {age }}=26.55 ; S D_{\text {age }}=\right.$ $4.53)$ - they were students and graduates of a variety of study fields - law, psychology, social work, electro-technology, geography, economy (further - lay people).

\section{Procedure}

The research procedure was in a form of software programed in Delphi 2010. In the first part, participants filled in demographics (sex, age, marital status, education, years of practice in the field, work position). In the second part, they were instructed to estimate the future returns of six stock indices (DAX, DJA, FTSE100, NIKKEI225, IBOVESPA, RTSI) in three forecasting periods of six months, nine months, and twelve months. When choosing stock indices, we tried to include the biggest well-known market indices but also to create the most diversified stock indices set in terms of geographical 
distribution. Additionally, one of the most important criteria when choosing indices was to include indices reporting profits but also losses. When evaluating the profitability of indices, we observed the past percentage returns for the last five years from the time of indices selection [14/3/2015]. In the group of indices reporting losses, we included RTSI Russian index, whose nominal value in the last five years decreased by $-39.49 \%$; and Brazilian index IBOVESPA, whose value decreased by $-24.15 \%$. Other indices in the last five years reported profits (FTSE 100: $+24.50 \%$; DJIA: $+75.09 \%$; Nikkei 225 : $+83.51 \%$; DAX: $+93.89 \%$ ).

When predicting future returns, participants could use a variety of information about stock indices. The research procedure contained 1) some basic information about index (number and characteristics of companies included, industry and business sectors that index reflects and what method is used in weighting index price);2) graphs of historical index prices in six months, one year, two years and five years (participant could also observe two most popular moving averages - simple and exponential moving average, which shows the direction of the historical trend in index price); 3 ) numerical data about historical index prices (current price, the lowest and highest price in the last year, data of historical prices for each month in the last five years and for each week in the last year).

\section{Measuring Excessive Optimism}

We used a classical method of estimating 95\% confidence intervals, which is widely used in the research on overconfidence when measuring miscalibration but also in observing excessive optimism (e.g., Menkhoff, Schmeling, \& Schmidt, 2013; Sonsino \& Regev, 2013; Toshino \& Suto, 2004). The participants were instructed as follows:

When predicting future index returns, you will provide the confidence intervals in which you are $95 \%$ sure that the future index return will fall in.

I predict with $95 \%$ probability that after $6(9$, 12) months the future percentage returns of index will be between __ $\%$ and __ $\%$.

Providing confidence intervals allowed us to analyze whether a real return after 6/9/12 months will fall within the estimated interval. If the real return was lower than the lower bound of interval, such prediction was considered excessively optimistic.

\section{Results}

The measure of excessive optimism was based on analyzing whether real future stock index returns fall into estimated confidence intervals. Participants provided their predictions from the date 14/03/2015. Table 1 shows the real percentage returns of chosen stock indices in the forecasted time period of six months, nine months and twelve months. Real returns were calculated as a simple difference between initial and final value in the particular time period without considering dividends, inflation and tax charges. We evaluated the excessive optimism of predictions according to real returns reported in Table 1.

When comparing past stocks indices returns (before 14/3/2015) with returns that were reported in our forecasted time periods, it is obvious that stock markets have not performed well. From all returns, there was only one very slight positive return in IBOVESPA stock index $(0.56 \%)$. Moreover, the highest losses were recorded mostly in stock indices that were the most profitable in the last five years (see Table 1).

When analyzing the accuracy of predictions of financial professionals and lay people, it seems that the negative stock markets trend was not expected by any of the observed groups. 
Table 1 Real percentage returns of stock indices in forecasted future time periods

\begin{tabular}{lccc}
\hline Stock index & $\begin{array}{c}\text { Percentage returns in } \\
\text { six months }\end{array}$ & $\begin{array}{c}\text { Percentage returns in } \\
\text { nine months }\end{array}$ & $\begin{array}{c}\text { Percentage returns in } \\
\text { one year }\end{array}$ \\
\hline DJIA & -7.77 & -2.15 & -2.93 \\
DAX & -14.87 & -14.81 & -16.06 \\
FTSE100 & -9.73 & -12.86 & -8.40 \\
RTSI & -2.99 & -8.70 & -0.36 \\
NIKKEI225 & -6.69 & -1.93 & -10.49 \\
IBOVESPA & -2.70 & -7.92 & +0.56 \\
\hline
\end{tabular}

Every participant provided 18 predictions. The analysis of variance $\left(F=78.73 ; p<.01 ; \eta^{2}=.39\right)$ showed that investment managers were the most accurate $(A M=8.6 ; S D=3.79)$, followed by the group of lay people $(A M=4.87 ; S D=$ $2.49)$, and financial advisors $(A M=2.51 ; S D=$ 2.28). Post hoc testing (LSD) showed that mean differences between all groups were significant $(p<.01)$.

When analyzing the frequency of correct predictions, we found that out of a total of 4518 predictions provided by all research participants, 3597 were incorrect (the actual return did not fall into provided interval). In addition, we found that of all the 3597 incorrect predictions, 3354 of them $(93.24 \%)$ were excessively optimistic. Table 2 shows the frequencies of pessimistic, correct and optimistic predictions about each stock index in three predicted future time periods made by three of the observed groups.

Of all provided predictions, $68.81 \%$ were excessively optimistic. Analysis of variance (Oneway ANOVA) was used to compare group differences in excessive optimism (the average number of optimistic predictions). We found a significant effect between the groups on excessive optimism $\left(F=60.71 ; p<.01 ; \eta^{2}=.33\right)$. The results of post-hoc testing (LSD) showed that mean differences between investment manag$\operatorname{ers}(A M=8.96 ; S D=3.84)$, advisors $(A M=14.68$; $S D=2.67)$, and lay people $(A M=11.81 ; S D=$ 2.79) were significant $(p<.01)$.

\section{Comparing Excessive Optimism of Stock In- dices Reporting Profits and Losses}

The chosen stock indices set contained indices that reported profits but also losses in the last five years. We compared excessive optimism of profitable (DAX, DJIA, FTSE100, NIKKEI225) and unprofitable (IBOVESPA, RTSI) group of indices. In every stock index, we calculated the percentage of excessively optimistic predictions and subsequently calculated mean of excessively optimistic predictions in a set of profitable and non-profitable stock indices. The results of Student t-test showed that predictions of unprofitable stock indices were significantly less optimistic, compared to the profitable indices (Table 3).

In next analysis, instead of comparing two groups of indices, we observed the relationship between excessive optimism (the percentage of excessively optimistic predictions) and the rate of profitability for the past 5 years. As we stated in methods, indices differed at this rate-RTSI: $-39.49 \%$; IBOVESPA: $-24.15 \%$; FTSE 100: +24.50\%; DJIA: +75.09\%; NIKKEI225: $+83.51 \%$; DAX: $+93.89 \%$. The results of Pearson correlation test showed a significant moderate relationship between the past profitability of index and excessive optimism in predicting its future returns $(r=.40$; $p<.01)$. 
Table 2 Frequencies of pessimistic, correct, and optimistic predictions in three predicted future time periods made by group of advisors, investment managers and lay people

\begin{tabular}{cccccccccc}
\hline \multirow{2}{*}{ Predictions } & \multicolumn{3}{c}{ Advisors } & \multicolumn{4}{c}{ Investment managers } & \multicolumn{3}{c}{ Lay people } \\
\cline { 2 - 10 } & Pes. & Correct & Opt. & Pes. & Correct & Opt. & Pes. & Correct & Opt. \\
\hline DAX1 & 0 & 3 & 92 & 0 & 8 & 37 & 0 & 6 & 105 \\
DAX2 & 0 & 3 & 92 & 0 & 7 & 38 & 0 & 3 & 108 \\
DAX3 & 0 & 2 & 93 & 0 & 2 & 43 & 0 & 0 & 111 \\
DJIA1 & 0 & 11 & 84 & 0 & 8 & 37 & 4 & 29 & 78 \\
DJIA2 & 0 & 31 & 64 & 0 & 25 & 20 & 6 & 46 & 59 \\
DJIA3 & 0 & 29 & 66 & 0 & 25 & 20 & 3 & 48 & 60 \\
FTSE1 & 0 & 5 & 90 & 0 & 23 & 22 & 6 & 31 & 74 \\
FTSE2 & 0 & 1 & 94 & 0 & 11 & 34 & 1 & 29 & 83 \\
FTSE3 & 0 & 0 & 95 & 0 & 0 & 45 & 5 & 0 & 106 \\
NIKKEI1 & 0 & 4 & 91 & 0 & 29 & 16 & 1 & 10 & 100 \\
NIKKEI2 & 2 & 16 & 77 & 1 & 41 & 3 & 6 & 27 & 78 \\
NIKKEI3 & 0 & 2 & 93 & 0 & 12 & 33 & 1 & 5 & 105 \\
IBOVE1 & 12 & 29 & 54 & 3 & 38 & 4 & 21 & 61 & 29 \\
IBOVE2 & 4 & 11 & 80 & 0 & 19 & 26 & 2 & 52 & 57 \\
IBOVE3 & 17 & 30 & 48 & 3 & 39 & 3 & 44 & 45 & 22 \\
RTSI1 & 14 & 24 & 59 & 4 & 38 & 3 & 16 & 51 & 44 \\
RTSI2 & 6 & 12 & 77 & 0 & 28 & 17 & 9 & 42 & 60 \\
RTSI3 & 22 & 25 & 48 & 9 & 34 & 2 & 21 & 58 & 32 \\
Frequency in \% & 4.50 & 13.90 & 81.60 & 2.48 & 47.77 & 49.75 & 7.24 & 27.15 & 65.61 \\
\hline
\end{tabular}

Note. In each name of stock index (column 1), the subsequent number means forecasted time period - number 1 means 6 months, 2 means 9 months, and 3 means 12 months

Table 3 Comparing excessive optimism in profitable and non-profitable stock indices

\begin{tabular}{lcccccc}
\hline Indices & $\mathrm{n}$ & $\mathrm{AM}$ & $\mathrm{SD}$ & Mean difference & $\mathrm{t}$ & $\mathrm{p}$ \\
\hline Non-profitable* $_{\text {Profitable** }}^{* *}$ & 251 & .44 & .35 & & & \\
\hline
\end{tabular}

* RTSI, IBOVESPA

** DAX, DJIA, FTSE, NIKKEI 


\section{Analyzing Excessive Optimism and Fore- casting Time Period}

Finally, we were interested whether more longterm predictions are more optimistic than shortterm predictions. As in the previous analyses, we calculated the percentage of excessively optimistic predictions and subsequently calculated the mean of excessively optimistic predictions in a set of six-month, nine-month and twelve-month predictions. We found that the proportion of optimistic predictions was rather high in all three forecasted horizons. It was shown that the proportion of optimistic predictions significantly increased $(t=3.55 ; p<.01)$ from the six-month $(A M=67.53 ; S D=23.48)$ to the nine-month horizon $(A M=70.85 ; S D=$ $22.98)$, but then significantly decreased $(t=2.96$; $p<.01)$ to a very similar level when predicting returns in a twelve-month horizon $(A M=68.06$; $S D=18.83$ ). When comparing excessive optimism in six-month and nine-month horizons the difference was not significant $(t=.53 ; p=.59)$.
In addition to analyzing the proportion of optimistic predictions, we were also interested whether these excessively positive predictions differed in the amount of optimism between three forecasted time periods, i.e. what is the distance between the lower bound of estimated interval and the real actual return of stock index (the greater the distance the more optimistic prediction). Therefore, we calculated and compared the mean difference of these two points in a set of six-months, nine-months and twelvemonths forecasts. When analyzing optimistic predictions in the whole sample, we found that the amount of optimism was highest in a ninemonth forecasted horizon. As in a previous analysis, we found a very similar pattern of predictions - the distance between lower bound of intervals and actual real indices return significantly increased from the six-month to the nine-month horizon, but then decreased significantly when predicting returns in a twelvemonth horizon (see Figure 1).

Besides the whole sample, we also conducted similar analyses in a group of investment man-

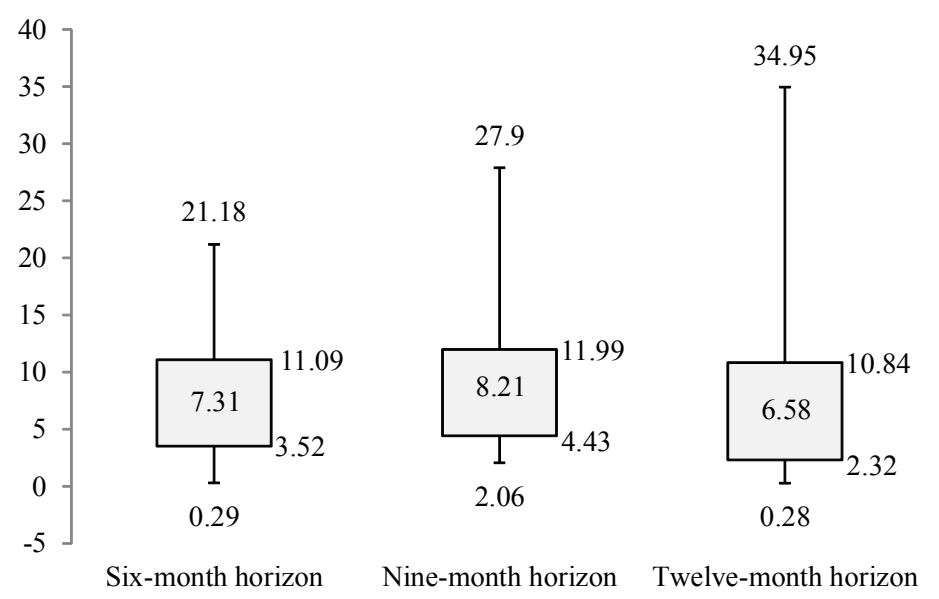

Figure 1 Comparing the amount of optimism of three forecasted horizons in the whole sample

Note. Graph illustrates the minimum and maximum, the lower and upper bound of standard deviation and the mean of distance between lower bound of estimated intervals and real actual index return in a group of six-months, nine-months and twelve-months predictions. 

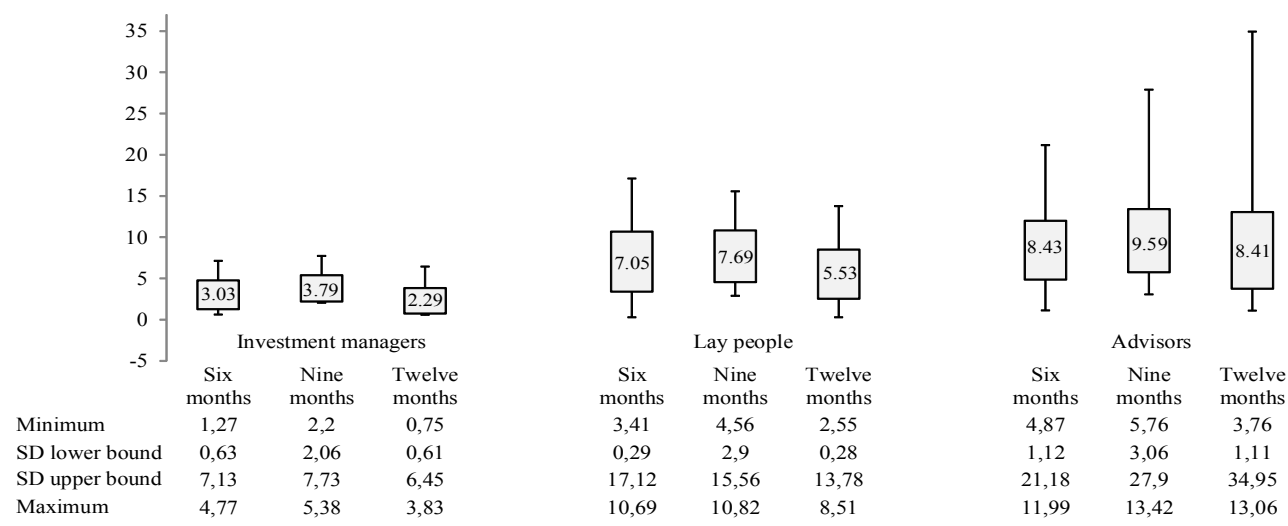

Figure 2 Comparing the amount of optimism of three forecasted horizons in each group separately

Note. Graph illustrates the mean of distance between lower bound of estimated intervals and real actual index return of three forecasted horizons in a group of investment managers, lay people and advisors. The table under the graph reports descriptive statistics about optimistic predictions in each forecasted horizon and each group separately.

agers, advisors and lay people separately. When comparing the groups, we found that in all three forecasted horizons, the least optimistic was a group of investment managers followed by lay people and advisors. Additionally, when observing the differences in the amount of optimism between three forecasted horizons in each group separately, we found a similar pattern as when analyzing the whole sample, i.e. the amount of optimism increased from the six-month to the nine-month horizon, but then decreased when predicting returns in a twelve-month horizon (see Figure 2).

\section{Discussion and Conclusion}

As we stated in the results, compared to the past five years the stock markets have not performed well. The analysis of excessive optimism showed that the decreasing trend in stock markets was not expected either in the group of financial professionals or in the group of lay people. Although financial professionals from the investment field manifested the least excessive optimism compared to other groups, their frequency of optimistic predictions was also rather high (almost 50\%). These results point to the systematic tendency of financial professionals to provide optimistic predictions as demonstrated by many authors (Shiller, 2000; Abarbanell \& Lehavy, 1993; DeBondt \& Thaler, 1990; Easterwood \& Nutt, 1999; Toshino $\&$ Suto, 2004). There could be one particular explanation of excessive optimism in the predictions of all participants and that is the underestimation of the probability of switch in stock markets trend. Fuster with his colleagues (see Fuster, Hebert, \& Laibson; 2011; Fuster, Hebert, \& Laibson 2012; Fuster, Laibson, $\&$ Mendel, 2010) argue that investors in the process of analyzing information unconsciously combine their intuitive insights with more rational deliberations and end up with natural expectations. As we stated before, these expecta- 
tions are characterized by overestimating the long-term persistence of good news or bad news. The economy (and also stock market returns) has a long-run hump-shaped dynamics that leads to a mean reversion, which is underestimated by investors (Fuster, Laibson, $\&$ Mendel, 2010). In other words, investors tend to overestimate more recent fundamentals and underestimate a possible reversion of returns to historical mean. This causes predictions in times of profit to be excessively optimistic. In our method, we provided participants graphs and numeric data about past performance of chosen stock indices. In four of these indices, graphs clearly illustrated a positive trend for the past five years. For example, in the last year NIKKEI225 stock index reported $+28.41 \%$ profit, DAX reached $+20.53 \%$ and DJIA reached $+12.59 \%$. When analyzing this information, participants could have overestimated the probability that this trend will continue in the next year and they could have underestimated the possibility of reversion of returns to historical mean (for comparison, NIKKEI225 has annualized average return of $+10.05 \%$ and DJIA $+5.36 \%$ ). Unfortunately we cannot confirm this interpretation from our data. It would require an experimental methodology, where different information about stock indices is manipulated. Especially, manipulating information about annualized average return of indices could result in the decrease of optimism in the forecasts.

The switch in the market trend could also cause our second hypothesis not being confirmed. According to the findings of other authors (Dowen, 1996; Hwang, Jan, \& Basu, 1996; Brown, 1998; Mande, Wohar, \& Ortman, 2003), we expected that predictions of returns of nonprofitable stock indices would be more optimistic compared to the profitable ones. Contrary to this, we found that the highest returns were predicted in the most profitable stocks indices. These results do not support previous findings of Hwang, Jan, and Basu (1996). In their re- search, excessive optimism in predictions of non-profitable stocks was ten times higher than in the predictions of profitable stocks. Our results showed the opposite tendency, and as stated, this could have been caused by the switch in the stock market trend. We found that participants predicted lower future returns to non-profitable stock indices compared to profitable indices. However, all stock indices in the following year reported losses, so naturally the negative predictions of non-profitable indices were less optimistic than those of profitable ones. When interpreting and comparing the results of other research on excessive optimism, the important aspect is to take market trends into account. Another important aspect is to distinguish stock indices and stocks. Yates, McDaniel, and Brown (1991) highlight that stock returns are very difficult to predict. The random walk theory states that stock market prices cannot be predicted because stocks price changes are independent of time and of each other. Prices move randomly and unpredictably so the historical movement or trend cannot be used to predict their future movement. Moreover, individual stock prices are much more volatile compared to the stock indices. Considering all these facts, it is very difficult to compare our results to the results of Hwang, Jan, and Basu (1996). Ten times higher optimism of non-profitable stocks compared to the profitable stocks in their research is rather high, but understandable.

In our last analysis we investigated whether long-term predictions are more optimistic than short-term predictions. When analyzing the frequency of optimistic predictions, but also the amount of optimism (i.e., the distance between lower bound of estimated interval and real actual return) of these predictions in the three forecasted horizons, we found a similar unexpected pattern. It was shown that all three groups tend to be most optimistic when forecasting ninemonth returns. The amount of optimism in- 
creased from the six-month to the nine-month horizon, but then decreased to a very similar level when predicting returns in a twelve-month horizon. This pattern was observed in the whole sample, but also in all three groups separately. We may conclude that our results do not support suggestions about the positive relationship between forecasted horizon and excessive optimism (Kang, O’Brien, \& Sivaramakrishnan, 1994; Ramnath, Rock, \& Shane, 2008). They do not even support previous empirical findings of Toshino and Suto (2004). In their research, participants predicted returns in a one-month and twelve-month horizon and it was shown that twelve-month horizon predictions were more optimistic. In our research, participants predicted returns in three different horizons and the time distances between these horizons were much shorter. This difference in methodology is the reason why we cannot fully compare these two results and it could also be the reason why our results were different from the results of Toshino and Suto (2004). As in their case, we also lack the theoretical explanation for our results. We can only speculate that when predicting a nine-month horizon from the time of indices selection [14/3/2015], participants could realize that they are forecasting the returns that will be in December/end of the year. In the literature, there is overwhelming evidence that abnormal equity returns are associated with the turn of the year (Jacobs \& Levy, 1988). This effect also occurs in stock markets, where the highest positive returns are during December and January (see e.g., Thaler, 1987; Marrett \& Worthington, 2011; Sander \& Veiderpass, 2013). In our research, participants could expect the highest returns in nine-month horizon just because of the season where this prediction fell in. However as we stated before, this interpretation is rather speculative; it would mean that our participants were very sensitive and, in a certain way, also very ecologically rational in predicting future stock indices returns. In the case of investment managers and advisors, this interpretation could be more accurate because of their practical knowledge and experience in the field of investment and finance. However, it is highly questionable whether lay people (even if they were mainly students of economics) possess such knowledge about markets functioning and if not, why they also predicted the highest returns in a nine-month horizon. We strongly emphasize the need for further examination of the relationship between forecasted horizon and excessive optimism.

Some of the research on predicting future equity returns found that forecasts of financial professionals are often more inaccurate compared to the lay people (Staël von Holstein, 1972; Yates, McDaniel, \& Brown, 1991; Menkhoff, Schmeling, \& Schmidt, 2013; Glaser, Langer, \& Weber, 2005). They hypothesized about an inverse effect of expertise in explaining this paradox. In this research, we found that despite the high frequency of optimistic predictions of all groups, the group of investment managers predicted returns of stock indices most accurately and their predictions were the least optimistic. When observing the methodology of research supporting the inverse effect of expertise, we think that this hypothesis could be misinterpreting because of the specific sample of "experts" included in these studies. Yates, McDaniel, and Brown (1991) in their research included and compared semi-experts (PhD students in finance) and non-experts (novice students in finance). Menkhoff, Schmeling and Schmidt (2013) included institutional investors, advisors and private investors. Finally, Glaser, Langer, and Weber (2005) included bankers and students. In each of these studies, the experts were more inaccurate compared to the lay people, except in the case of institutional investors in the work of Menkhoff, Schmeling, and Schmidt (2013). However, when analyzing the variety of experts included in these studies, only in this one particular case could we con- 
sider the group of institutional investors as real financial professionals in the field of investment. It is highly questionable whether $\mathrm{PhD}$ students in finance, advisors, or bankers should be considered experts in investment field. We could assume that compared to the institutional investors, they lack the practical knowledge and experience in portfolio managing and also experience in technical and fundamental analysis of assets or markets. Our sample consisted of very similar groups to those in the work of Menkhoff, Schmeling, and Schmidt (2013) and our results were very similar as well. As in their research, institutional investors were the most accurate, followed by the lay people and advisors/bankers. From our point of view, the specific samples of "semi-experts" (bankers, advisors), which in fact have a very limited knowledge about investing, could bias the interpretation of the inverse effect of expertise in predicting. In other words, we could assume that a certain limited knowledge or expertise in a much related field (finance) could paradoxically lead to more inaccurate predictions. Additionally, our results and also the results of Menkhoff, Schmeling, and Schmidt (2013) clearly showed that direct practical experience with analyzing and predicting future prices of equities could lead to more accurate predictions. When testing the hypothesis of inverted expertise effect, we highlight the importance of carefully distinguishing between various financial professionals. Finally as Menkhoff, Schmeling, and Schmidt (2013) stated, we also suggest that investment advisors and bankers should be considered financial professionals, but only with some caution.

\section{References}

Abarbanell, J., \& Lehavy, R. (2003). Biased forecasts or biased earnings? The role of reported earnings in explaining apparent bias and over/underreaction in analysts' earnings forecasts. Journal of Accounting and Economics, 36, 105-146.
Baer, G., \& Gensler, G. (2002). The great mutual fund trap. NY: Broadway Books.

Barber, B., \& Odean, T. (2001). Boys will be boys: Gender, overconfidence, and common stock investment. The Quarterly Journal of Economics, 116, 261-292.

Ben-David, I., Graham, J. R., \& Harvey, C. R. (2010). Managerial miscalibration. NBER working paper 16215 .

Bradshaw, M. T. (2011). Analysts' forecasts: What do we know after decades of work? Retrieved from: http://psc.ky.gov/pscecf/2012-00221/ rateintervention@ag.ky.gov/10252012c/ Bradshaw,_Analysts_forecasts_-_What_we_know_2011.pdf

Brown, L. D. (1998). Managerial behavior and the bias in analysts' earnings forecasts. Working paper, Georgia State University.

DeBondt, W. (1998). A portrait of the individual investor. European Economic Review, 42, 831-844.

DeBondt, W., \& Thaler, R. (1985). Does the stock market overreact? Journal of Finance, 40, 793 805 .

DeBondt, W., \& Thaler, R. (1990). Do security analysts overreact? American Economic Review, 80, 52-57.

Dowen, R. J. (1996). Analyst reaction to negative earnings for large well-known firms: Systematic differences for negative and non-negative earnings firms. Journal of Portfolio Management, 23(1), 49-55.

Easterwood, J., \& Nutt, S. (1999). Inefficiency in analysts' earnings forecasts: Systematic misreaction or systematic optimism. Journal of Finance, 54, 17771797.

Francis, J., \& Philbrick, D. (1993). Analysts' decisions as products of a multi-task environment. Journal of Accounting Research, 31, 216-230.

Fuster, A., Hebert, B., \& Laibson, D. (2011). Natural expectations, macroeconomic dynamics, and asset pricing. NBER Working Paper No. 17301. Retrieved from: http://www.frbsf.org/economic-research/files/ Fuster-Hebert-Laibson.pdf

Fuster, A., Hebert, B., \& Laibson, D. (2012). Investment dynamics with natural expectations. International Journal of Central Banking, 8(81), 243265.

Fuster, A., Laibson, D., \& Mendel, B. (2010). National expectations and macroeconomic fluctuations. Journal of Economic Perspectives, 24(4), 67-84.

Glaser, M., Langer, T., \& Weber, M. (2005). Overconfidence of professionals and lay men: Individual differences within and between tasks? Mannheim: Sonderforschungsbereich 504, Working Paper.

Heaton, J. B. (2002). Managerial optimism and corporate finance. Financial Management, 31, 33-45. 
Hilary, G., Hsu, C., \& Segal, B. (2013). The bright side of managerial over-optimism. Insead: The Business School for the World. Faculty \& Research Working Paper. Retrieved from: http://www.insead.edu/ facultyresearch/research/doc.cfm?did $=52779$

Hilton, D., Regner, I., Cabantous, L., Charalambides, L., \& Vautier, S. (2011). Do positive illusions predict overconfidence in judgment? A test using interval production and probability evaluation measures of miscalibration. Journal of Behavioral Decision Making, 24(2), 117-139.

Hwang, L., Jan, CH., \& Basu, S. (1996). Loss firms and analysts' earnings forecast errors. Journal of Financial Statement Analysis, 1(2), 18-30.

Jacobs, B. I., \& Levy, K. N. (1988). Calendar anomalies: Abnormal returns at calendar turning points. Financial Analysts Journal, 44(6), 28-39.

Kafayat, A. (2014). Interrelationship of biases: Effect investment decisions ultimately. Theoretical and Applied Economics, 22(6), 85-110.

Kang, S., O’Brien, J., \& Sivaramakrishnan, K. (1994) Analysts' interim earnings forecasts: Evidence on the forecasting process. Journal of Accounting Research, 32, 103-112.

Kohout, P. (2013). Investični strategie pro třetí tisíciletí. Praha: Grada Publishing, a.s.

Kothari, S. P. (2001). Capital markets research in accounting. Journal of Accounting and Economics, $31,105-231$.

Liang, Y., Ramchander, S., \& Sharma, J. L. (1995). The performance of stocks: Professional versus dartboard picks. Journal of Financial and Strategic Decisions, 8(1), 55-63.

Lin, W. C., Chang, S. C., Chen, S. S., \& Liao, T. L. (2013). The over-optimism of financial analysts and the long-run performance of firms following private placements of equity. Finance Research Letters, 10, 82-92.

Malkiel, B. G. (2016). A random walk down Wall Street. The time-tested strategy for successful investing. NY: W. W. Norton \& Company, Inc.

Mande, V., Wohar, M. E., \& Ortman, R. F. (2003). An investigation of asymmetric earnings forecasts of Japanese financial analysts. Multinational Business Review, 11(1), 13-43.

Marrett, G., \& Worthington, A. (2011) The monthof-the-year effect in the Australian stock market: A short technical note on the market, industry and firm size impacts. Australasian Accounting, Business and Finance Journal, 5(1), 117-123.

Menkhoff, L., Schmeling, M., \& Schmidt, U. (2013). Overconfidence, experience and professionalism: An experimental study. Journal of Economic Behavior \& Organization, 86, 92-101.

Michaely, R., \& Womack, K. (1999). Conflict of interest and the credibility of underwriter analyst recommendations. Review of Financial Studies, 12, 653-686.

Ramnath, S., Rock, S., \& Shane, P. (2008). The financial analyst forecasting literature: A taxonomy with suggestions for further research. International Journal of Forecasting, 24, 34-75.

Sander, P., \& Veiderpass, R. (2013). Testing the turnof-the-year effect on Baltic stock exchanges. The Review of Finance and Banking, 5(2), 145-154

Sharpe, S. A. (2002). Reexamining stock valuation and inflation: The implications of analysts' earnings forecasts. Review of Economics and Statistics, 84(4), 632-648.

Shefrin, H. (2007). Behavioral corporate finance. Decisions that create value. New York: McGraw Hill.

Shiller, R. J. (2000). Irrational exuberance. New Jersey: Princeton University Press.

Sonsino, D., \& Regev, E. (2013). Informational overconfidence in return prediction - More properties. Journal of Economic Psychology, 39, 72-84.

Staël Von Holstein, C. A. S. (1972). Probabilistic forecasting: An experiment related to the stock market. Organizational Behavior and Human Performance, 8, 139-158.

Thaler, R. H. (1987). Anomalies: The January Effect. The Journal of Economic Perspectives, 1(1), 197-201.

Toshino, M., \& Suto, M. (2004). Cognitive biases of Japanese institutional investors: Consistency with behavioral finance. Tokyo: Waseda University, Institute of Finance, Working Paper Series.

Wang, J., Sheng, J., \& Yang, J. (2013). Optimism bias and incentive contracts in portfolio delegation. Economic Modelling, 33, 493-499.

Weinstein, N. D. (1980). Unrealistic optimism about future life events. Journal of Personality and Social Psychology, 39, 806-820.

Yates, J. F., McDaniel, L. S., \& Brown, E. S. (1991). Probabilistic forecasts of stock prices and earnings: The hazards of nascent expertise. Organizational Behavior and Human Decision Processes, 49, 60-79. 